\title{
Self-Awareness and the Evolution of Leaders: The Need for a Better Measure of Self-Awareness
}

\author{
Greg C. Ashley \\ Bellevue University \\ Roni Reiter-Palmon \\ University of Nebraska at Omaha
}

\begin{abstract}
A growing body of empirical research suggests that self-awareness is associated with successful leadership. Although self-awareness research has generated a number of scales to measure selfawareness, none have done so with the explicit focus of leadership. The present research is a summary of three studies designed to develop and begin validation for a scale to measure self-awareness in the context of leadership and leader development. The result of Study 1 and 2 was a 54-item self-awareness scale. A confirmatory factor analysis provided evidence for a marginal fit. Predictive validity was assessed in Study 3 by looking for associations between self-awareness and outcomes from an MBA capstone course designed in part to improve communication, foster teamwork, and increase self-awareness. Selfawareness was the independent variable. The dependent variables were the graded, videotaped outcomes of two types of structured role-playing exercises designed to meet course objectives and involved students working in dyads or in small groups. Positive associations were found between the new scale and some group context measures of performance, but not for the dyad measures. Implications and suggestions for future research are provided.
\end{abstract}

\section{Introduction}

The construct of self-awareness has been taken up by a wide array of academic disciplines, suggesting that self-awareness may explain variance in a number of domains. Although definitions vary, selfawareness is an inwardly-focused evaluative process in which individuals make self/standard comparisons with the goal of better self-knowledge and improvement. The scope of the present writing is focused on how self-awareness may be related to the context of leadership, specifically leader development. As will be discussed, empirical support is mounting suggesting that self-awareness is related to leadership such that leaders higher in self-awareness tend to get better outcomes than those with lower levels of self-awareness. Given the increasing attention self-awareness processes are getting from leadership theorists, a scale to measure self-awareness may be of value. As such, the specific purpose of the present writing is to discuss the development of a scale to measure self-awareness.

\section{Historical Relevance of Self-Awareness}

Humans have a unique capacity to contemplate not only their status quo, but also their ideal status quo. This capacity is underpinned by the ability to imagine a future that is better than the past, evaluate alternatives, identify problems, and a yearning to progress toward an ideal. Intertwined are processes of self-reflexive thought, self-examination, and introspection. All of the above broadly circumscribe the construct of self-awareness, and although conceptualizations of self-awareness do vary, at their core is an ability to focus attention inward and study oneself as though looking in a mirror.

The relevance of self-awareness cannot be overstated. In fact, Leary and Buttermore (2003) theorize that the capacity for self-reflection may have been one of essential drivers for the remarkably rapid appearance of human civilization 40,000 - 60,000 years ago. Leary and Buttermore attribute the explosive growth in human culture and technological advances during this time to a nascent capacity to think symbolically and abstractly about oneself and to ponder the changes required to move toward a better future. 
Not surprisingly, there has been a long-standing and cross-cultural interest in self-awareness by philosophers, social scientists, clinicians, and more recently, leadership theorists. Writings on the self are known from China as early as $500 \mathrm{BC}$ and from India as early as $600 \mathrm{BC}$, to name just a few (Leary \& Tangney, 2003). More modern seminal treatments of self-awareness by psychologists and sociologists can be seen in the works of James (1890), Mead (1934), Cooley (1956), and Duval and Wicklund (1972). Although each of these modern writers has a nuanced view of self-awareness, a common theme emerges suggesting that individuals view themselves as both observers and subjects of observation. Moreover, individuals often use a reflective process whereby they imagine themselves from the vantage point of another with the goal of comparing self-evaluations against others' evaluations. Specifically, Mead and Duval and Wicklund theorize that individuals have a motivated desire for accurate assessment of self-worth or progress against a goal or standard. As such, the effective use of self-awareness processes would seem to be of great relevance to leadership scholars.

The discussion will unfold as follows. First, a short discussion on how self-awareness has been conceptualized, and specifically how it might be conceptualized in a leadership context. Second, a case will be made as to why we should care about self-awareness, including evidence showing the relation between self-awareness and leader outcomes, and also why we need a new measure. Third, a discussion regarding the construction of a self-awareness measure, including psychometric properties. Lastly, a study demonstrating partial support for the predictive validity of the present measure.

\section{What Is Self-Awareness and Why Do We Care?}

Various conceptualizations of self-awareness have emerged over time with newer formulations often adding nuances on previous versions. As a starting point, consider Duval and Wicklund's (1972) theory of objective self-awareness (OSA). According to original OSA theory, individuals periodically focus attention inward and begin a comparison process to assess themselves against a salient standard (e.g., a behavior or progress toward a goal). OSA predicted the likely outcome of such a comparison would be the identification of a self/standard gap, which in turn would lead to negative affect. The self/standard comparison involved processes of introspection and self-evaluation (Ickes, Wicklund, \& Ferris, 1973).

In one of the first attempts to develop a scale to measure self awareness, Fenigstein, Scheier, and Buss (1975) suggested the following dimensions: "(a) preoccupation with past, present, and future behaviors; (b) sensitivity to inner feelings; (c) recognition of one's positive and negative attributes; (d) introspective behavior; (e) a tendency to picture or imagine oneself; ( $f$ ) awareness of one's physical appearance and presentation; and (g) concern over the appraisal of others" (p. 523). A three-dimensional structure emerged in the final scale and the dimensions were labeled as private self-consciousness (e.g., "I reflect about myself a lot"), public self-consciousness (e.g., "I'm concerned about what others think of me"), and social anxiety (e.g., "Large groups make me nervous").

Several researchers used the Fenigstein et al. (1975) scale as a departure point for revisions regarding self-awareness dimensionality. Burnkrant and Page (1984), for example, theorized that the private selfconsciousness factor was better specified as a two-dimensional construct containing dimensions labeled as self-reflection and internal state awareness. The latter included "such feelings as tranquility, elation, and depression as well as such bodily events as heartbeat and breathing" (p. 631). Additional analyses by Burnkrant and Page using different participant pools demonstrated better fit using the revised dimensionality than Fenigstein et al's. model.

As can be discerned from the discussion thus far, earlier researchers considered self-awareness processes as predominantly cognitive in nature. Trapnell and Campbell (1999) viewed this as a gap and believed that in addition to cognition, it was also necessary to consider motivational and emotional influences. In other words, the reasons for engaging in self-awareness were important as well. Trapnell and Campbell note that individuals may increase levels of self-awareness based either on neurotic-like tendencies (e.g., anxiety) or for purposes of gaining self-knowledge or personal growth.

As part of their justification for including motivational/emotional influences, Trapnell and Campbell (1999) cited a large body of research suggesting that high levels of self-awareness paradoxically can result in either good or bad outcomes (see also Pyszczynski, Hamilton, Greenberg, \& Becker, 1991). On the 
positive side, high self-awareness has been shown to have psychotherapeutic effects and enables individuals to better adjust to their environment. On the contrary, high self-awareness also is associated with a number of maladies like depression and anxiety. According to Trapnell and Campbell's line of reasoning, outcomes are influenced by the motivational disposition for engaging in self-awareness. Hence, research by Trapnell and Campbell suggests the private self-consciousness factor is better viewed as two dimensions, which they labeled rumination and reflection. In summary, the review of literature above leaves open the possibility that self-awareness processes are an amalgam of both cognitive and affective influences.

An additional divergence in the way self-awareness has been conceptualized concerns the trait versus state distinction. Fenigstein et al. (1975) thought self-awareness could be both, labeling the trait form as self-consciousness and the state form as self-awareness. Other self-awareness researchers have used mirrors and cameras to manipulate (i.e., increase) levels of self-awareness, thus implying that selfawareness has state-like properties. Self-awareness also has been conceptualized as a skill (Church, 1997b) which suggests that interventions could be used to increase self-awareness. Self-awareness also has been viewed as a cognitive schema (Church, 1997a) where self-awareness outcomes might vary based on context or relationships.

The construct of self-awareness also has been included as part of the dimensionality of two different conceptualizations of emotional intelligence (i.e., Dulewicz \& Higgs, 2000; Goleman, 2004). Of note is that these authors tend to view emotional intelligence as a competency that can be learned and which explains variance in leader outcomes. As pertaining to the specific dimension of self-awareness, a competency-based view is consistent with the cognitive and state distinctions discussed above, thus suggesting trainability.

Some researchers have given less priority to teasing out nuances in self-awareness conceptualizations, but rather were more focused on self-awareness outcomes. In such instances, self-awareness often has been defined simply as self/other agreement (e.g., Van Velsor, Taylor, \& Leslie, 1993). For example, those leaders whose self-report ratings of performance are similar to performance ratings ascribed to them by others are defined operationally as having high levels of self-awareness. Using this operational standard, a large body of empirical research has accrued suggesting those managers with high levels of self-awareness tend to have better performance outcomes than those with lower levels of self-awareness (e.g., Atwater, Ostroff, Yammarino, \& Fleenor, 1998; Bass \& Yammarino, 1991; Furnham \& Stringfield, 1994). Moreover, congruence between subordinates' evaluation of their manager and the managers' selfevaluation may lead to increased levels of subordinate satisfaction (Wexley, Alexander, Greenawalt, \& Couch, 1980). The gestalt of self/other congruence research suggests that increased congruence between self versus other ratings is amenable to interventions, for example, by increasing salience on the value of feedback.

Taken as a whole, the preponderance of literature discussed above tends to suggest that self-awareness is trainable. To the extent that self-awareness might be increased via an intervention, a new scale to measure self-awareness designed specifically for the context of leadership may be useful for the study of leadership in general and leader development in specific.

\section{Why Do We Need Another Scale?}

A new scale is needed because existing scales are too parsimonious, do not speak to the complexity of self-awareness processes, and only partially tap into the dimensionality of self-awareness that operates in a leadership context. As such, each of the existing scales discussed above has desirable aspects but is not complete. For example, while the Fenigstein, Scheier, and Buss (1975) scale does recognize the notions of self-reflection and attention to inner thoughts and feelings, nothing is considered regarding the reasons for engaging in self-awareness (i.e., motivational factors), nor is there any discussion where or how standards are developed or accepted. In like manner, the Burnkrant and Page (1984) and Trapnell and Campbell (1999) views of self-awareness are mute on the topic of standard setting, do not provide a framework for why self-examination begins, and do not consider an individual's desire to detect self/standard gaps. 
In the leadership context, the effectiveness of self-awareness outcomes turns on developing or accepting specific standards along with a strong desire for accurate self-evaluation. Regarding standard setting, a noteworthy shortcoming of existing scales is lack of recognition that standards may be nuanced beyond the self by multiple relevant stakeholders. The acceptance of any standard, internal or external, requires an understanding of one's strengths and weaknesses, and this self-knowledge is not addressed in existing scales. Moreover, because standard setting may in part be exogenous to the individual, it makes sense that additional attention to accuracy is warranted because the foci of evaluation likewise are external to the individual. The ability to integrate both internal and external standards and still make accurate self/standard comparisons may explain why research related to self/other congruence has noted positive outcomes for leaders high in self-awareness.

An additional gap with existing self-awareness measures concerns the way in which current conceptualizations of self-awareness deal with the presence of affect. While some existing conceptualizations do acknowledge the presence of affect, none considers the possibility of affect as the subject of self-awareness, that is, as a relevant dimension of self that can be assessed against an ideal. Lastly, existing scales presume a narrow view of personality where simple behaviors are assessed against a one-dimensional standard. In reality, self-awareness processes are multifaceted and may include a wide array of strengths and weakness, for example, self-awareness of thinking styles.

The foregoing review was the primary theoretical underpinning for the beginning development of the present scale, which started with Study 1.

\section{Study 1: Initial Scale Construction}

The primary task of Study 1 was to conceptualize the dimensionality of self-awareness in the specific context of leader development. One of the defining hallmarks of self-awareness that appears in nearly all conceptualizations of self-awareness is the notion that individuals evaluate themselves against some salient standard or goal. At its core, self-awareness is the process that signals whether an individual needs to moderate a behavior, emotion, or course of action. In other words, the outcome of a selfawareness episode may signal the need for self-regulation. Although the value of self-regulation in a leadership context hardly needs explication, the focus here is on the decision processes used to refine and nuance the salient standard or goal. In short, effective leaders need to integrate the standards and goals of relevant stakeholders (e.g., bosses, subordinates, peers, and customers) into their own selfregulatory processes (Tsui \& Ashford, 1994).

Based on the foregoing concepts, and focusing to the context of leadership, the initial dimensionality of self-awareness was theorized to include (a) a recognition of internal and external standards, (b) a recognition of one's positive and negative attributes/abilities, (c) a desire for introspective and selfreflective thought, and (d) a desire for accurately detecting gaps in personal behaviors, traits, and goal progress.

As is typical in scale development, participants also were asked to complete several additional scales measuring related constructs where theory and/or prior empirical findings suggest relevance in order to help establish validity. In this regard, four existing measures of self-awareness were selected. Correlations between these scales and the present scale were expected to be in the moderate range because of modest crossover with the present scale, but yet not reflecting the same dimensionality.

Additional measures included were creativity, emotional intelligence, empathy, feedback seeking, generalized self-efficacy, locus of control, metacognition, and need for cognition (specific details are provided in the Measures section below). Self-awareness processes include a desire to identify self/standard gaps, hence creativity is relevant because creative ideas are those that are both original and useful. As such, individuals must be able to determine whether an idea meets standards (i.e., is a useful idea). In this regard, constructs that help to capture performance-related cues from the environment also are useful, for example, feedback seeking, emotional intelligence, and empathy. The process of setting standards and the accompanying self/standard evaluation is likely to be cognitively 
intense at times such that an individual high in need for cognition would benefit more (i.e., enhancing selfawareness) than those individuals low on this trait. This logic also applies to metacognition. Lastly, locus of control and general self-efficacy were included because effective leaders are assumed to be high on these constructs. Weak to neutral correlations were hypothesized for scales measuring depression/anxiety, self-monitoring, and socially desirable responding. As regards depression/anxiety, known empirical links to self-awareness appear to be underpinned on many different factors such as an unreasonable/unrealistic comparison standard, rumination, and/or inaccurate evaluation of self/standard progress. The dimensionality of the present scale is likely to preclude these underpinnings to depression/anxiety primarily because of the focus on accuracy. As regards self-monitoring and socially desirable responding, these are processes that focus attention primarily outward and only are tangentially concerned with accuracy of self-appraisal. As such, correlations with the present measure should be minimal.

\section{Study 1 Method}

Participants. Participants were recruited from introductory psychology courses at a large Midwestern university. The sample size was 419 and was composed of mostly white freshman, sophomores, and juniors (mean age 21.8, SD = 4.9; 134 males, 285 females). Participant responses were collected using an internet-based commercial survey tool commonly used in social science research (i.e., SurveyMonkey).

Measures. Self-awareness scale items for the present scale were generated from two sources. First, $1 / O$ psychology faculty and graduate students familiar with the research generated items by dimension. This process resulted in 62 useable items. Second, a pilot study was conducted that included a biographical essay related to self-awareness. The essay was designed to capture retrospective self-reports of events in participants' life experiences that might be related to self-awareness but may have been overlooked by the item writers. An additional nine items were generated from the self-reports, resulting in a final draft of 71 items.

Three of the four existing self-awareness measures which were included as part of the validation process already were discussed above, specifically, the Fenigstein, Scheier, and Buss' (1975) self-consciousness scale, Burnkrant and Page's (1984) self-reflection / internal state awareness scale, and Trapnell and Campbell's (1999) rumination / reflection scale. A fourth measure of self-awareness included was Grant, Franklin, and Langford's (2002) self-reflection / insight scale.

Other related, established constructs were measured using the following existing scales; creativity (Runco, Noble, \& Luptak, 1990), depression/anxiety (Costello \& Comrey, 1967), emotional intelligence (Wong \& Law, 2002), empathy (Davis, 1980), feedback seeking (Tuckey, Brewer, \& Williamson, 2002), generalized self-efficacy (Chen, Gully, \& Eden, 2001)locus of control (Rotter, 1966), metacognition (Schraw \& Dennison, 1994), need for cognition (Cacioppo, Petty, \& Kao, 1984), self-monitoring (Snyder, 1974), and socially desirable responding (Crowne \& Marlowe, 1960). The foregoing scales were selected in part because they evinced acceptable levels of reliability which also were supported in the present research (see Table 1). 
Table 1

Reliabilities of Related Scales Included in Present Research.

Full Scale Reliabilities

\begin{tabular}{|c|c|c|}
\hline Scale & Original & Present Research \\
\hline Self-Consciousness & .80 & .82 \\
\hline Self-Reflection/Internal State Awareness & Not reported & .81 \\
\hline Rumination/Reflection & .90 & .93 \\
\hline Self-Reflection/Insight & $.91 / .87^{*}$ & .90 \\
\hline Creative Activities Checklist & Ranged .64 to $.91^{*}$ & .91 \\
\hline Depression/Anxiety & $.90 / .70^{*}$ & $.94 / .85$ \\
\hline Emotional Intelligence & Ranged .83 to. $90^{*}$ & .89 \\
\hline Empathy & Ranged .71 to $.77^{*}$ & .83 \\
\hline Feedback & $.82^{\dagger}$ & .89 \\
\hline Generalized Self-Efficacy & .86 & .90 \\
\hline Locus of Control & Ranged .49 to .84 & .69 \\
\hline Metacognition & Ranged .88 to $.93^{*}$ & Ranged .87 to .94 \\
\hline Need for Cognition & .90 & .89 \\
\hline Self-Monitoring & .70 & .62 \\
\hline Socially Desirable Responding & Ranged .73 to .88 & .72 \\
\hline
\end{tabular}

${ }^{*}=$ not reported for full scale but by dimension

${ }^{\dagger}$ The Feedback Seeking scale was composed of four dimensions, however, the present research only used the desire for useful information dimension which is shown above.

\section{Study 1 Results}

Exploratory factor analysis. An exploratory factor analysis (EFA) was conducted using Varimax rotation despite no prior assumption regarding orthogonality. Although 4, 7, and 12 factor solutions emerged, the 4-factor solution had fewer crossloadings and was much easier to interpret than that the seven and twelve-factor solutions. Total variance explained by the four factors equaled $27 \%(10.6 \%, 7.8 \%, 4.7 \%$, and $3.8 \%$ respectively). 
The dimensionality evinced by the EFA was similar but not identical to the proposed dimensionality. A comparison of theoretical versus empirical dimensionality is provided in Table 2 which highlights two dissimilarities. First, a dimension related to accuracy of self-evaluation was not apparent. Second, an unexpected dimension emerged that can be described as an indifference toward the use of external cues for purposes of self-evaluation.

Table 2

Hypothesized Dimensions of Self-Awareness versus EFA Dimensions.

EFA Dimensions Hypothesized Dimensions

Self-critical

Desire for realistic awareness Indifference to external cues

Self-reflection
Recognition of internal and external standards

Recognition of one's positive and negative attributes/abilities

Introspection and self-reflection

Accurately detecting gaps in personal behaviors, traits, and goal progress

The Cronbach alpha for the entire scale was .85 (individual factors ranged from .73 to .83 ). Correlations between the four factors ranged from small and insignificant to a high of .38 .

\section{Correlations between Present Self-awareness Scale and Other Measures}

Correlations between the present self-awareness scale and all of the included measures discussed above are shown in Table 3. Correlations between the present self-awareness scale and the four existing selfawareness measures ranged from .37 to .57 . These correlations are moderate and not as high as would be expected from scales that are measuring the same construct.

Correlations between the present self-awareness measure and the remaining measures also are shown in Table 3. Taken as a whole, these measures provided additional support for validity. In particular, note the low correlation between the present measure and socially desirable responding $(r=-.16)$. This result suggests that a negligible amount of variance was explained by socially desirable responding.

Table 3

Correlations between the Present Self-Awareness Scale $(\mathrm{N}=44)$ and the other Included Measures $(N=375)$.

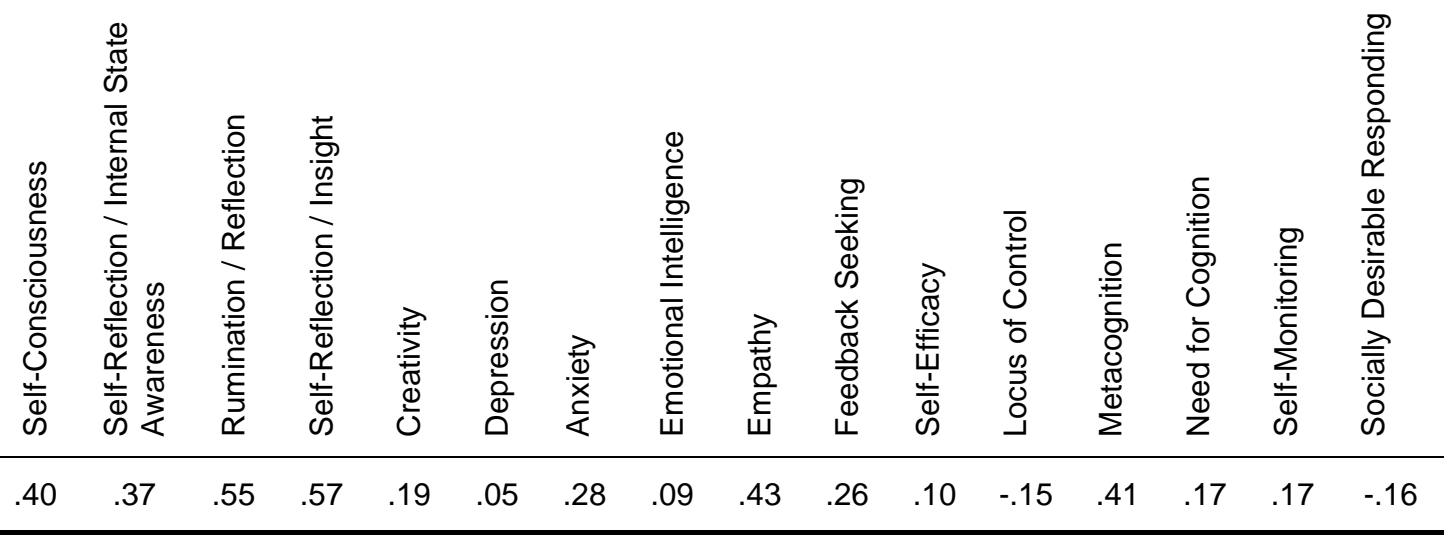

Note. All correlations were significant to at least the $. p<0.05$ level except for the depression measure which was not significant. 


\section{Study 1 Discussion}

The overall pattern of correlations evinced in Study 1 was consistent with the literature review above that suggested self-awareness is composed of both cognitive and affective components. First, the dimensionality found in the EFA, in addition to positive correlations with constructs thought to be cognitive in nature (e.g., metacognition), suggests that self-evaluation does engage cognitive processes. These processes are required to establish standards and make realistic comparisons between one's present progress versus the desired or optimal progress. Second, correlations with anxiety and empathy suggest that being self-aware is not without emotion. Conceptually, the notion of emotional outcomes seems reasonable when considering that the core of self-awareness processes is concerned with self/standard gaps, and this line of reasoning is consistent with prior self-awareness theory (e.g., Duval and Wicklund, 1972).

Despite the empirical gleanings provided by Study 1, a critical review of the work indicated some gaps. First, the dimensionality evinced in the EFA was similar but still not completely representative of ex ante theory. This result, in combination with the unexplainable EFA dimension labeled indifference to external cues, suggested a possible need to revisit the theoretical dimensionality of self-awareness in a leadership context. The outcome of this review suggested that the original conceptualization of self-awareness may have been missing the dimension of insight. In other words, it seems likely that self-awareness processes ultimately need to reach a synthesis or conclusion in order to be effective, something that might be called the "a-ha" moment. After all, what good is an episode of self-reflection if nothing comes of it? Note also that Grant et al. (2002) included insight in their measure of self-awareness and that the insight dimension of their scale was positively correlated with the present self-awareness measure. Two additional studies were designed to address these gaps.

Study 1 also did not include a confirmatory factor analysis (CFA). As such, a CFA was conducted in Study 2 with the goal of further clarifying the factor structure and providing additional empirical support for the scale.

A second gap with Study 1 was a test of criterion validity. As noted above, a large body of evidence has accrued suggesting that high levels of self-awareness are associated with positive outcomes for leaders. If this is true, then the present measure of self-awareness should correlate with objective measures of performance. Study 3 was designed as an empirical test of this premise.

\section{Study 2}

The first task of Study 2 was to conduct a pilot study with the goal of clarifying the factor structure of selfawareness in the present context. A second, goal of the pilot study was to develop a short form of the scale that was more practical for use in research.

\section{Pilot Study Method}

Participants. Participants were recruited and selected using the same methodology in Study 1 . The final sample included 93 males and 183 females $(n=276)$ with an average age of $23.5(S D=7.4)$.

Measure. Additional scale items related to insight were generated using the same basic methodology as in Study 1. Thirteen usable items were culled from an initial list of 100 and added to the 71 -item scale from Study 1 , for a total of 84 items.

\section{Pilot Study Results}

An EFA was conducted using Oblimin rotation. Two and five factor solutions emerged with the latter being much easier to interpret. Moreover, the five factor solution was much more consistent with a priori theory. The factors were named as follows; self-critical, insight, self-reflection, feedback seeking, and performance indifference. The latter factor was composed of items suggesting an indifference to performance-related events. Total variance explained by the five factors was $30.4 \%(10.2 \%, 8.5 \%, 4.3 \%$, $3.8 \%$, and $3.6 \%$ respectively). 
As mentioned above, one goal for Study 2 was to develop a measure that was shorter and more practical to use. The full measure contained over 80 items and was perceived as taking too long to administer in many contexts. A 54-item short form was developed by retaining only those items that loaded at least .40 on the respective factor (see Appendix for items). Cronbach alphas for both the long and short form are provided in Table 4. There was no appreciable loss in reliability in going to the short form. The additional validation efforts of Study 2 were conducted on the short form.

Table 4

Cronbach alphas for self-awareness long and short form measure $(N=276)$

\begin{tabular}{lcc}
\hline & Long Form & Short Form \\
\cline { 2 - 3 } Self-Critical & .858 & .849 \\
Insight & .798 & .789 \\
Self-Reflection & .793 & .799 \\
Feedback Seeking & .737 & .734 \\
Performance Indifference & .752 & .704 \\
Full Scale & .841 & .822 \\
\hline
\end{tabular}

Study 2: CFA

A series of CFAs were conducted on data obtained from a usable sample of 426 participants (average age $=21.6, S D=4.8 ; 154$ males, 272 females) that were recruited and surveyed using the same methodology as discussed above. Model fit was assessed using four commonly used model fit assessments; comparative fit index (CFI), Tucker-Lewis index (TLI), goodness of fit index (GFI), and root mean square area of approximation (RMSEA). Hard cutoffs have not been established regarding what is and is not a good fit, however, general guidelines suggest values $\leq .05$ are ideal for RMSEA and values between .05 and .08 are within reason (Kline, 2000). The remaining indexes are thought to have good fit for values $\geq .90$ (Cheung \& Rensvold, 2002; Kline, 2000).

Study 2 CFA results and discussion. CFA results are shown in Table 5. The first model tested was orthogonal in which the five factors were not allowed to correlate. A second non-orthogonal was tested as well. As seen in Table 5, the fit of these models was under generally accepted rules of thumb for good model fit. Two additional models were tested in an attempt to see whether the large number of items might have suggested a larger sample size. The first of these was a model using only the five highest loading items on each factor. The second used a composite approach in which scale items were systematically combined. The fit of these two latter models came close to achieving the model fit rule of thumb standards discussed above, thus suggesting an approximate but not ideal fit.

\section{Study 3: Criterion Validity}

The primary goal for Study 3 was to test the predictive validity of the present measure. Such a test would benefit from a controlled setting where objective measures of performance were possible. Student outcomes from a capstone course in the MBA program of a major Midwestern university designed to develop essential management skills were used as a criterion measure. This course was residential (i.e., not online). Specific objectives of the course included (a) teaching interpersonal skills associated with managing direct reports, (b) improving the quality of communications, (c) increasing self-awareness levels in managers, and (d) developing teamwork. All of these management skills are assumed to be trainable, including self-awareness. The gestalt of the preceding literature review support the notion of trainability, 
as well as the finding from Study 1 that self-awareness has a cognitive component, thus suggesting that self-awareness is not exclusively a trait characteristic.

Congruent with the literature review above and consistent with the outcomes of the prior studies, three specific hypotheses were put forth regarding outcomes of this course designed to increase leadership skills.

Hypothesis 1: Levels of self-awareness will increase between the beginning and end of the course.

Hypothesis 2: Self-awareness will be positively correlated with objective measures of performance in the course.

Hypothesis 3: Students beginning the course with higher levels of self-awareness will benefit more from the course than those with lower levels of self-awareness.

Table 5

Results of CFA Analyses as Measured by Several Commonly-Used Model Fit Indices $(n=425)$

\begin{tabular}{llllllll} 
Model & $X^{2}$ & $\mathrm{df}$ & $\mathrm{CFI}$ & $\mathrm{TLI}$ & $\mathrm{GFI}$ & $\mathrm{RMSEA}$ & $\mathrm{c} . \mathrm{i}$. \\
\hline Orthogonal & $3945, \mathrm{p}<.01$ & 1377 & .613 & .598 & .724 & .066 & $.064-.069$ \\
Non-Orthogonal & $3499, \mathrm{p}<.01$ & 1367 & .679 & .664 & .759 & .061 & $.058-.063$ \\
5 Highest Loads & $719, \mathrm{p}<.01$ & 265 & .825 & .802 & .875 & .064 & $.058-.069$ \\
Composite & $893, \mathrm{p}<.01$ & 289 & .846 & .827 & .860 & .070 & $.065-.075$ \\
\hline
\end{tabular}

Note. $\mathrm{CFI}=$ Comparative Fit Index; TLI = Tucker-Lewis Index; GFI = Goodness of Fit Index; RMSEA = Root Mean Square Area of Approximation.

\section{Participants}

Participants were students enrolled in three sections of the MBA course described above. Usable data were collected from 59 participants (mean age $=27.6, S D=6.1 ; 37$ males, 22 females).

\section{Measures}

Self-awareness was measured using the short form of the self-awareness measure as discussed above. Outcome variables in the course were of two types, both involving video recorded role-playing exercises of students dealing with common business problems. The first type of exercise was a dyad consisting of a student role-playing a manager who is addressing performance issues with another student who is roleplaying a subordinate. In specific, the outcome variable was a rating of how each student role-playing the manager compared against a taxonomy of specific, expected behaviors identified as part of the course objectives. This dyad measure hereafter is referred to as the individual measure of performance.

The second type of exercise was a group exercise where students role-played managers attempting to solve a business problem. This outcome variable also was a rating of how well students aligned with a checklist of behaviors but it is important to note that the ratings were applied separately to each individual in the group and not the group per se. Hereafter this measure will be referred to as the group context measure of performance.

Two different types of raters rated the outcome variables described above. First, the professors teaching the course provided a rating for each of their respective students (i.e., rated only their own classes) for both the individual and group context measures. These raters are referred to as internal raters. A second group of raters consisted of I/O psychology doctoral students, hereafter referred to as external raters. The external raters rated all of the student participants, however, a modified checklist was used to allow for more information to be collected. As such, detailed interrater reliability was not possible except between the external raters ( $\alpha=.62$ for the individual measure and $\alpha=.58$ for the group measure).

\section{Procedure}




\section{SELF-AWARENESS AND THE EVOLUTION OF LEADERS}

The short form self-awareness measure was administered to students at both the beginning and end of the course and was used as the IV to test the three hypotheses. The DV variables were provided by the rated outcome variables of the MBA class.

\section{Analyses}

Hypothesis 1 used a paired-samples $t$-test to determine whether the pre/post measures of self-awareness were statistically different. Hypothesis 2 used a correlation to determine the level of association between the measure of self-awareness and the individual and group context measures. Hypothesis 3 used a median split of the pre measure of self-awareness to test for differences in the outcome variables. Tests to check for significant differences between the low versus high performance split were done using a $t$ test for both the individual and group context measures.

\section{Results and Discussion}

Hypothesis 1 tested for differences in self-awareness between the beginning and end of the course. The pre/post difference was not significant, thus Hypothesis 1 was not supported $\left(t_{(49)}=0.39, p<.35\right)$. Lack of support for Hypothesis 1 raises several questions. First, on the reasonable assumption that selfawareness can be trained, what length of time is required to do it? Is one course enough, especially a course that had other objectives in addition to increasing self-awareness? Second, is one mode of training more efficacious than others? In other words, does the artificial context of a classroom setting provide the ideal methodology to increase self-awareness? Third, development of any kind, including selfawareness, is likely to require motivated, goal-oriented effort. Attempts to control for the potential of this latter confound were not done in this research.

Hypothesis 2 posited that self-awareness would be positively correlated with objective measures of performance. The group context measures of individual performance are shown in Table 6 and provided partial support for Hypothesis 2. A more detailed view of the relations that includes the various subdimensions of self-awareness also is provided in Table 6.

Table 6

Correlations of Self-Awareness with Group Measure Performance $(n=56)$

\begin{tabular}{lcc}
\hline & Internal Ratings & External Ratings \\
\hline PostSC & $.34^{*}$ & .23 \\
PostIN & -.01 & -.12 \\
PostRE & .02 & .05 \\
PostFE & $.29^{*}$ & .17 \\
PostPI & .13 & $.28^{*}$ \\
PostTot & $.27^{*}$ & $.21^{\dagger}$ \\
\hline
\end{tabular}

${ }^{*}=\mathrm{p}<.05$ (1-tailed) ${ }^{* *}=p<0.01$ (1-tailed) $\dagger=p<0.06$ (1-tailed).

Note. $\mathrm{SC}=$ average self-critical; $\mathrm{IN}=$ average insight; $\mathrm{RE}=$ average self-reflection; $\mathrm{FE}=$ average

feedback; $\mathrm{PI}=$ average performance indifference (reversed); Tot = combined average.

Of first note is that the overall measure of self-awareness (average score across all dimensions) was significantly correlated with the internally-rated measure of performance $(r=.27)$ and almost reached a level of significance with the externally-rated measure $(r=.21, p=.06)$. Note that the low sample size may have been a contributing factor to the marginal correlation (i.e., insufficient power). Among the subdimensions, the self-critical factor had the strongest correlations with performance and the result was consistent across rater types $\left(r_{\text {internal }}=.34\right.$ and $r_{\text {external }}=.23$ ). The only correlations that were not significant for both kinds of raters were the insight and reflection subdimensions. Taken as a whole, the measures of student performance found in Table 6 suggest that higher levels of self-awareness are related to better individual outcomes in group settings. 
Results for the measures of performance involving dyad interactions were not supportive of Hypothesis 2. None of correlations between self-awareness and these measures of performance were significant. This outcome is inconsistent with the group context findings and may be a function of the difference between the dynamics of dyadic interaction versus group interaction. In other words, the increased social density of latter, replete with multiple interactions and relationships to manage, may be more likely to activate self-awareness processes than would a dyadic situation. Taken together, the results provide partial support for hypothesis 2.

Hypothesis 3 posited that individuals starting a leadership development course with higher levels of selfawareness would result in better outcomes than individuals starting with lower levels of self-awareness. This test used a median split based on the pre-measure of self-awareness to create two different criterion groups (low versus high) for both the individual and group context performance measures. Group differences were checked using independent samples $t$-tests (see Table 7). A significant difference between the low versus high groups was found both for the internally-rated (i.e., course instructors) group context performance measure and the externally-rated individual performance measure. No significant differences were found for either the externally-rated group context measure or the internally-rated individual measure.

One possible explanation for the mixed results could be related to range restriction in the both the pre and post measures of self-awareness. The range of the pre measure was only .93. and the post measure range was 1.30 . Homogeneity of the participant sample may have contributed to this restriction. The majority of the sample was white students aged between 23 and 28 with a limited amount of real-world work experience.

Table 7 Independent Samples t-Tests of Significance in Criterion DV Created Based on a Median Split of the PreSelf-Awareness Measure $(n=59)$

\begin{tabular}{lccrl}
\hline DV Pairs & Mean (Low) & Mean (High) & $\mathrm{t}$ & Sig. \\
\hline External Rated Individual Measure & -0.05 & 0.09 & -1.68 & .05 \\
Internal Rated Individual Measure & 0.88 & 0.87 & 1.08 & .14 \\
External Rated Group Measure & -0.04 & -0.00 & -0.47 & .32 \\
Internal Rated Group Measure & 0.85 & 0.90 & -2.75 & $<.01$ \\
\hline
\end{tabular}

Note. One-tailed tests, $d f=57$.

\section{General Discussion}

Studies 1 and 2 helped to more thoroughly specify the theoretical dimensionality of self-awareness in a leadership context by providing a test of model fit. Study 3 demonstrated partial support for the notion that self-awareness is related to leader-related outcomes. The less than optimal model fit from the CFA, along with mixed outcomes for the predictive validity tests in Study 3suggest that additional work is needed. The litany of apparent paradoxes that has emerged in past as well as present self-awareness research has demonstrated a full range of desirable, undesirable, and neutral outcomes and is a testament to the complexity of self-awareness processes.

Overcoming the difficulty in developing a tighter measure of self-awareness may require ongoing thought regarding the dimensionality of self-awareness process and the associated research designs required to expect effects. Regarding the latter, do levels of self-awareness increase gradually and consistently, or are increases catapulted forward, perhaps from defining experiences or traumatic events? Are real-world situations more engendering of self-awareness development than classroom settings? The diversity of individuals, tasks, problems, and frustrations in the workforce, for example, is likely to be much richer than those found in formal training contexts. In short, it may be more appropriate to conduct self-awareness in real-world contexts than in pure academic contexts.

The present self-awareness scale provides a departure point for studying the effects of self-awareness on leader outcomes. Although the research discussed above is suggestive that more due diligence is warranted, the present scale provides a better approach for the study and understanding of self- 
awareness in leaders than the other measures not designed for this purpose. This was accomplished by considering the specific self-awareness processes that are likely to be associated with effective leadership. Although complex, the self-awareness construct has shown great promise as one of many factors associated with leadership successes.

\section{Practical Implications}

Practitioners may find value in using the present scale to test for possible associations with outcomes of their leader development programs as well as other various performance outcome measures. If the scale can explain variance then this might have implications for hiring and promotion decisions, as well as organizational training and development efforts.

Related to this, practitioners may also find the present scale helpful in doing leader-related root cause analysis. For example, Van Velsor and Leslie (1995) in a review of causes for leader derailments document four superordinate causes for failure: (a) interpersonal relationship problems, (b) not meeting objectives, (c) team leadership breakdowns, and (d) inability to adapt to transitions and changes. Although a good case can be made that self-awareness is related to all four of these causes, selfawareness especially is important in the context of adaption, transition, and changes because this context speaks most directly to the issue of self/standard gaps. In other words, there may be many situations where a measure of self-awareness explains variance in failures as well as successes. To the extent this is true then mitigation efforts can be put in place.

\section{References}

Atwater, L. E., Ostroff, C., Yammarino, F. J., \& Fleenor, J. W. (1998). Self-other agreement: Does it really matter? Personnel Psychology, 51, 577-598.

Bass, B. M., \& Yammarino, F. J. (1991). Congruence of self and others' leadership ratings of naval officers for understanding successful performance. Applied Psychology: An International Review, 40, 437-454.

Burnkrant, R. E., \& Page, T. J. (1984). A modification of the Fenigstein, Scheier, and Buss selfconsciousness scales. Journal of Personality Assessment, 48, 629-637.

Cacioppo, J. T., Petty, R. E., \& Kao, C. F. (1984). The efficient assessment of need for cognition. Journal of Personality Assessment, 48, 306-307.

Chen, G., Gully, S. M., \& Eden, D. (2001). Validation of a new general self-efficacy scale. Organizational Research Methods, 4, 62-82.

Cheung, G. W., \& Rensvold, R. B. (2002). Evaluating goodness-of-fit indexes for testing measurement invariance. Structural Equation Modeling, 9, 233-255.

Church, A. H. (1997a). Do you see what I see? An exploration of congruence in ratings from multiple perspectives. Journal of Applied Social Psychology, 27, 983-1020.

Church, A. H. (1997b). Managerial self-awareness in high-performing individuals in organizations. Journal of Applied Psychology, 82, 281-292.

Cohen, J. (1988). Statistical power analysis for the behavioral sciences (2nd ed.). Hillsdale, NJ: Lawrence

Erlbaum Associates.

Cooley, C. H. (1956). Two major works: Social organization. Human nature and the social order. Glencoe, III.,: Free Press.

Costello, C. G., \& Comrey, A. L. (1967). Scales for measuring depression and anxiety. Journal of Psychology, 66, 303-313.

Crowne, D. P., \& Marlowe, D. (1960). A new scale of social desirability independent of psychopathology. Journal of Consulting Psychology, 24, 349-354.

Davis, M. H. (1980). A multidimensional approach to individual differences in empathy. JSAS Catalog of selected documents in psychology, 10, 85.

Dulewicz, V., \& Higgs, M. (2000). Emotional intelligence: A review and evaluation study. Journal of Managerial Psychology, 15(4), 341-372.

Duval, S., \& Wicklund, R. A. (1972). A theory of objective self awareness. New York: Academic Press.

Fenigstein, A., Scheier, M. F., \& Buss, A. H. (1975). Public and private self-consciousness: Assessment and theory. Journal of Consulting and Clinical Psychology, 43, 522-527. 


\section{SELF-AWARENESS AND THE EVOLUTION OF LEADERS}

Furnham, A., \& Stringfield, P. (1994). Congruence of self and subordinate ratings of managerial practices as a correlate of supervisor evaluation. Journal of Occupational and Organizational Psychology, $67,57-67$.

Goleman, D. (2004). What makes a leader? Harvard Business Review, 82(1), 82-91.

Grant, A. M., Franklin, J., \& Langford, P. (2002). The self-reflection and insight scale: A new measure of private self-consciousness. Social Behavior and Personality, 30, 821-836.

Ickes, W. J., Wicklund, R. A., \& Ferris, C. B. (1973). Objective self-awareness and self-esteem. Journal of Experimental Social Psychology, 9, 202-219.

James, W. (1890). The principles of psychology. New York: H. Holt and company.

Kline, R. B. (2005). Principles and practice of structural equation modeling (2nd ed.). New York: The Guilford Press.

Leary, M. R., \& Buttermore, N. R. (2003). The Evolution of the Human Self: Tracing the Natural History of Self-Awareness. Journal for the Theory of Social Behavior, 33, 365-404.

Leary, M. R., \& Tangney, J. P. (2003). The self as an organizing construct in the behavioral and social sciences. In M. R. Leary \& J. P. Tangney (Eds.), Handbook of self and identity (pp. 3-14). New York: The Guilford Press.

Mead, G. H. (1934). Mind, self \& society from the standpoint of a social behaviorist. Chicago, III.,: The University of Chicago Press.

McEnrue, M. P., Groves, K. S., \& Shen, W. (2007). Emotional intelligence development: Leveraging individual characteristics. Journal of Management Development, 28(2), 150-174. doi: 10.1108/02621710910932106

Pyszczynski, T., Hamilton, J. C., Greenberg, J., \& Becker, S. E. (1991). Self-awareness and psychological dysfunction. In C. R. Snyder \& D. R. Forsyth (Eds.), Handbook of social and clinical psychology: The health perspective (pp. 138-157). New York: Pergamon.

Rotter, J. B. (1966). Generalized expectations for internal versus external control of reinforcement. Psychological Monographs, 80, 1-28.

Runco, M. A., Noble, E. P., \& Luptak, Y. (1990). Agreement between mothers and sons on ratings of creative activity. Educational and Psychological Measurement, 50, 673-680.

Schraw, G., \& Dennison, R. S. (1994). Assessing metacognitive awareness. Contemporary Educational Psychology, 19, 460-475.

Snyder, M. (1974). Self-monitoring of expressive behavior. Journal of Personality and Social Psychology, 30, 526-537.

Trapnell, P. D., \& Campbell, J. D. (1999). Private self-consciousness and the five-factor model of personality: Distinguishing rumination from reflection. Journal of Personality and Social Psychology, 76, 284-304.

Tsui, A. S., \& Ashford, S. J. (1994). Adaptive self-regulation: A process view of managerial effectiveness. Journal of Management, 20, 93-121.

Tuckey, M., Brewer, N., \& Williamson, P. (2002). The influence of motives and goal orientation on feedback seeking. Journal of Occupational and Organizational Psychology, 75, 195-216.

Van Velsor, E., Taylor, S., \& Leslie, J. B. (1993). An examination of the relationships among selfperception, accuracy, self-awareness, gender, and leader effectiveness. Human Resource Management, 32(2-3), 249-263.

Van Velsor, E., \& Leslie, J. B. (1995). Why executives fail: Perspectives across time and cultures. Academy of Management Executive, 9, 62-72.

Wexley, K. N., Alexander, R. A., Greenawalt, J. P., \& Couch, M. A. (1980). Attitudinal congruence and similarity as related to interpersonal evaluations in manager-subordinate dyads. Academy of Management Journal, 23(2), 320-330.

Wong, C.-S., \& Law, K. S. (2002). The effects of leader and follower emotional intelligence on performance and attitude: An exploratory study. The Leadership Quarterly, 13, 243-274. 


\author{
Appendix \\ Scale Items for Short Form (54 items)
}

\title{
Factor 1 Name: Self-Critical
}

01 When you make a mistake to what extent has it tended to disrupt your day?

03 To what extent have you found yourself dwelling over minor social mistakes?

13 How difficult has it been for you to accept the fact that you were not as good at something as you thought you were?

14 How difficult has it been for you to cope with situations that forced you to see yourself in a different way?

16 How important has it been for you to receive praise from others?

24 How often do you compare your standards to those of others?

25 How often do you criticize your own work?

27 How often do you feel guilty when you have not performed to standards?

30 How often do you question your abilities?

31 How often do you reflect on your performance standards after a failure?

34 How often do you compare your performance to the performance of others?

37 How often do you assess whether you "belong" in a given situation?

38 How often has an emotional or difficult situation caused you to reassess your strengths and weaknesses?

40 When entering new situations, have you often found yourself worrying about your qualifications?

\section{Factor 2 Name: Insight}

06 To what extent are you aware of your own values and beliefs?

07 To what extent do you reflect on the things you like to do?

08 To what extent do you understand how your characteristics and your experiences have led to you becoming the person you are today?

09 To what extent do you understand how your personal characteristics lead to your behavior in different situations?

10 To what extent do you use diverse perspectives to arrive at new conclusions about yourself?

12 To what extent would your friends describe you as someone who knows themselves well?

19 After a major accomplishment how likely are you to sit back and enjoy the moment?

20 How likely are your friends to say that you know yourself well?

28 How often do you know what qualities you bring to a relationship?

29 How often do you modify your standards in order to improve performance?

39 When working on a project, how often can you tell in advance what part would be the easiest for you?

\section{Factor 3 Name: Reflection}

11 To what extent would you say that you consciously think about the ways your thoughts and emotions influence your behavior?

18 How likely are your friends to describe you as introspective?

22 How often did you spend time alone in high school so you could have time to think?

35 How often do you enjoy time alone because it allows you to reflect on your day's activities?

47 How often do you set time aside to reflect on your day?

48 How often do you ponder over how to improve yourself from knowledge of previous experiences?

49 I integrate information about myself from different sources to better understand myself?

50 I often find myself searching internally for explanations of my behavior and emotions?

51 How frequently have the outcomes of your behavior in a given situation caused you to reach an "a-ha" moment about yourself?

53 Relative to your friends, how much time do you spend trying to understand yourself?

54 Relative to your friends, how much time do you spend thinking about the reasons for your behaviors?

\section{Factor 4 Name: Feedback}

02 To what extent have you used feedback from your professor or boss to improve your performance?

04 To what extent do you like instructors or bosses to provide feedback?

05 To what extent do you enjoy participating in activities that are challenging? 
23 How often do you check with someone (advisor, teacher) to see if you're on the right track?

32 How often do you seek feedback regarding the quality of your work?

33 How often do you set personal goals?

44 How often has criticism resulted in a significant improvement in your performance?

45 How often do you write down your goals and track your progress towards them?

\section{Factor 5 Name: Performance Indifference}

15 How difficult has it been for you to criticize your own performance?

17 How likely are you to accurately tell if your work will meet the standards for your supervisor?

21 How often are your standards for work higher than the standards others have for you?

26 How often do you decrease the difficulty of your goals to make them more attainable?

36 How often have you used other's level of interest in a given activity to help you decide the level of your own interest?

41 In school, when assigned a project, how often do you put in only enough effort to get a passing grade?

42 How often were you surprised by a grade you received in a course?

43 How often have you been surprised by requests for help from friends?

46 How often do you turn down a project because it is beyond your abilities?

52 When you are upset, how long does it take you to figure out what caused it?

Response formats (items were grouped by response format):

Items 1 - 12: Not At All

Slight Extent

Moderately Extent

Large Extent

To a Great Extent

Item 16: Not At All Important

Slightly Important

Moderately Important

Somewhat Important

Extremely Important

Items 21 - 50: Never

Rarely

Sometimes

Frequently

Always

Item 52: $\quad$ Very Little Time

A Little Time

Some Time

A Long Time

A Very Long Time
Items 13-15: Not At All Difficult

Slightly Difficult

Moderately Difficult

Somewhat Difficult

Extremely Difficult

Items 17 - 20: Extremely Unlikely

Unlikely

Neither Likely Nor Unlikely

Likely

Extremely Likely

Item 51: Never

Rarely

Sometimes

Frequently

Always

Items 53 - 54: Much Less Time Relative To My Friends

Less Time Relative To My Friends

Same Time Relative To My Friends

More Time Relative To My Friends

Much More Time Relative To My Friends 
Reproduced with permission of the copyright owner. Further reproduction prohibited without permission. 